\title{
DON SANTIAGO DE LA IGLESIA Y EL DESCUBRIMIENTO DEL YACIMIENTO ARQUEOLÓGICO DE AS PONTES*
}

\author{
CÉSAR CANDELAS-COLODRÓN \\ Biblioteca Universitaria Casa do Patín (Universidade da Coruña) \\ ORCID iD: https://orcid.org/0000-0001-9953-6320
}

* Agradecimiento a Isaac Giz Pulgar por la reproducción de las ilustraciones.

Copyright: (C) 2020 CSIC. La edición electrónica de esta revista se distribuye bajo los términos de una licencia de uso y distribución Creative Commons Reconocimiento 4.0 Internacional (CC BY 4.0).

Cómo citar/Citation: César CANDelas-Colodrón, "Don Santiago de la Iglesia y el descubrimiento del yacimiento arqueológico de As Pontes", Cuadernos de Estudios Gallegos, 67, núm. 133 (2020), págs. 287-317, https://doi.org/10.3989/ceg.2020.133.10 


\section{DON SANTIAGO DE LA IGLESIA Y EL DESCUBRIMIENTO DEL YACIMIENTO ARQUEOLÓGICO DE AS PONTES (A CORUÑA)}

\section{RESUMEN}

Se presenta la transcripción del manuscrito en el que Santiago de la Iglesia da noticia del descubrimiento y primera excavación del yacimiento arqueológico de As Pontes en 1893. En él se constata la existencia de un considerable número de túmulos, dólmenes y hasta tres círculos líticos, uno de ellos de más de $20 \mathrm{~m}$ de diámetro. Entre los hallazgos asociados a este yacimiento destaca un vaso campaniforme completo, único en su especie en aquel momento, una diadema de oro, una maza ceremonial trilobulada, varias puntas de cobre y algunas hachas de piedra. Se ofrece también una detallada descripción de los túmulos y dólmenes, su forma y composición, ilustrada con dibujos realizados por el propio autor. Preceden a la transcripción unas notas breves sobre el contexto y sobre el autor del manuscrito.

Palabras Clave: Historia de la arqueología, campaniforme, círculo lítico, Edad del Bronce, yacimiento lacustre, Galicia.

\section{DON SANTIAGO DE LA IGLESIA E O DESCUBREMENTO DO XACEMENTO ARQUEOLÓXICO DAS PONTES (A CORUÑA)}

\section{RESUMO}

Preséntase a transcrición do manuscrito no que Santiago de la Iglesia da nova do descubrimento e primeira escavación do xacemento arqueolóxico das Pontes en 1893. Constátase nel a existencia dun considerable número de mámoas e ata tres círculos líticos, un deles de máis de $20 \mathrm{~m}$ de diámetro. Entre os achados asociados a este xacemento, destaca un vaso campaniforme completo, único na súa especie naquel momento, unha diadema de ouro, unha maza cerimonial trilobulada, varias puntas de cobre e algunhas machadas de pedra. Ofrécese tamén unha detallada descrición das mámoas, a súa forma e composición, ilustrada con debuxos realizados polo propio autor. Preceden á transcrición unhas notas breves sobre o contexto e sobre o autor do manuscrito.

Palabras Clave: Historia da arqueoloxía, campaniforme, círculo lítico, Idade do Bronce, xacemento lacustre, Galicia.

\section{DON SANTIAGO DE LA IGLESIA AND THE DISCOVERY OF THE ARQUEOLOGICAL SITE OF AS PONTES (A CORUÑA)}

\section{ABSTRACT}

Here is the transcription of the manuscript in which Santiago de la Iglesia gives news of the discovery and first excavation of the archaeological site of As Pontes in 1893. In this manuscript he verified the existence of a considerable number of mounds, dolmens and up to three lithic circles, one of them more than $20 \mathrm{~m}$ in diameter. Among his findings is a complete bell beaker, unique in its kind at that time, a gold diadem, a ceremonial tri-lobed mace, several copper arrowheads and some stone axes. It almost offers a detailed description of the mounds and dolmens, their shape and composition, illustrated with drawings made by the author himself. The transcription is preceded by some short notes about the context and the author.

KEY wORDs: History of the archaeology, Bell beaker, lithic circle, Bronze Age, lacustrine site, Galicia. 
Recibido/Received: 02/08/2019

Aceptado/Accepted: 07/02/2020

\section{El descubrimiento del yacimiento arqueológico de As Pontes}

La primera noticia sobre la existencia de un relevante yacimiento arqueológico en As Pontes de García Rodríguez (A Coruña) la dio don Leandro de Saralegui ${ }^{1}$ en la tercera edición de sus Estudios sobre la época céltica en Galicia (Ferrol, 1894). Ya en aquel momento no dudó en calificarlo como el yacimiento más importante del antiguo Reino por el número y circunstancias de los monumentos de esta clase que se conservan en su suelo, atribuyendo su hallazgo y las consecuentes primeras exploraciones a nuestro ilustrado y laborioso amigo D. Santiago de la Iglesia $^{2}$. El escaso tiempo transcurrido entre el descubrimiento (verano de 1893) y la publicación de la obra de Saralegui, da una idea de la inmediatez con la que Santiago de la Iglesia dio a conocer el suceso, de la velocidad con la que esta noticia se expandió entre sus amigos y correspondientes, y del impacto que la misma produjo en aquel círculo de ilustrados. Por don Federico Maciñeira ${ }^{3}$ sabemos que algunas de aquellas personas tuvieron acceso a las notas de excavación, y que viajaron hasta As Pontes para comprobar in situ la importancia del hallazgo y realizar sus propias prospecciones. El mismo Maciñeira fue uno de aquellos afortunados que recibieron cumplida información de primera $\mathrm{mano}^{4}$, aunque luego

\footnotetext{
1 Leandro de Saralegui y Medina (1839-1910), fue un marino gallego que hizo carrera en el Cuerpo Administrativo de la Armada. Erudito, autodidacta y militante en el regionalismo liberal, dedicó gran parte de su extensa obra a la historia (más bien protohistoria) de Galicia, a la que dotó de un pasado precelta (al que pretenecería el objeto de estudio de don Santiago de la Iglesia), lo que no dejaba de ser una novedad y un cierto atrevimiento en la Galicia de fines del siglo XIX. Para una idea sobre la relevancia de esta persona, v. Fernando Pereira González, "O pensamento arqueolóxico e antropolóxico de Leandro Saralegui y Medina (1839-1910)", Cuadernos de Estudios Gallegos, vol. 43, núm. 108 (1996), págs. 9-33.

2 Leandro Saralegui y Medina, Estudios sobre la época céltica en Galicia, $3^{\mathrm{a}}$ ed., Ferrol, Imprenta y librería de R. Pita, 1894, pág 276.

3 Federico Maciñeira y Pardo de Lama, "Notable grupo de círculos líticos y túmulos dolménicos de la cuenca superior del Eume", Arquivos do Seminario de Estudos Galegos, 2 (1929), pág. 211.

4 Don Santiago de la Iglesia puso a su disposición el magnífico ejemplar de vaso campaniforme, sin duda el principal hallazgo de la estación arqueológica de As Pontes, dándole así la oportunidad de estudiarlo, fotografiarlo y darlo a conocer (Federico MACIÑEIRA Y PARDO DE LAMA, "Investigaciones prehistóricas en Galicia”, La Ilustración Artística, 684 (1895), pág. 126).
} 
tardara cincuenta años ${ }^{5}$ en corroborar las palabras de Saralegui. Entonces reconocerá que el médico ferrolano y distinguido naturalista D. Santiago De la Iglesia había estado al menos un año antes que él en A Veiga dos Mouros (Vilavella) excavando algunos de los túmulos que formaban parte del yacimiento de aquel valle ${ }^{6}$.

Y es que tal como veremos confirmado en el texto que aquí aparece transcrito por vez primera, en el verano de 1893 don Santiago de la Iglesia Santos (18511931) recibió en Ferrol noticia del hallazgo y expolio de un dolmen en el que unos lugareños del vecino As Pontes habrían encontrado unas hachas de piedra pulimentada. La oportunidad, la cercanía o la intuición llevaron a don Santiago a trasladarse sin pérdida de tiempo, según sus propias palabras, al lugar del suceso. No habría de arrepentirse. Allí se encontró con un yacimiento arqueológico de gran envergadura que en realidad resultaron ser dos, situados a muy poca distancia uno del otro. El primero de ellos estaba en el valle (Veiga da Vilavella), y en él llegó a contar hasta 13 túmulos, alguno de los cuales contenían piezas de incalculable valor histórico, sobresaliendo entre ellas dos vasos campaniformes que durante un tiempo fueron ejemplares únicos en el NW peninsular. El segundo yacimiento, en A Mourela, estaba en la cumbre de uno de los montes que rodean ese mismo valle, en una posición dominante sobre éste, y allí encontró tres círculos líticos a los que no dudó en identificar como crómlech, uno de ellos también único en la Península Ibérica por sus más de $20 \mathrm{~m}$ de diámetro.

Hoy, cuando ya nada de esto queda, rescatamos aquí el recuerdo de aquellos yacimientos y de su descubrimiento y primera excavación por el Dr. de la Iglesia a través de la transcripción del manuscrito que él mismo redactó para dejar memoria del suceso.

\subsection{El polígrafo don Santiago de la Iglesia y Santos}

Don Santiago de la Iglesia ${ }^{7}$ nació en Santiago de Compostela, aunque muy pronto se trasladó con su familia a A Coruña, donde comenzó sus estudios. Destacó

\footnotetext{
5 Federico MaciñeIRA y PaRdo de Lama, "Túmulos prehistóricos. Inventario descriptivo de los doscientos ochenta y seis túmulos prehistóricos hasta ahora descubiertos en la avanzada comarca del Cabo Ortegal”, Boletín de la Real Academia Gallega, t. 24, núm. 277-280 (1944), pág. 22.

6 Como veremos, también estuvo antes en el yacimiento de A Mourela, donde identificó por vez primera tres círculos líticos, aunque don Federico Maciñeira se atribuyera su descubrimiento en 1895 (...dos magnificos cromlechs que hallamos en la notable estación de Puentes de García Rodríguez (Federico MACIÑEIRA Y PARDo DE LAMA, "Investigaciones prehistóricas en Galicia II". La Ilustración Artística, 687 (1895), pág.174) y 1929 (...tuve la suerte de tropezar, explorando la altiplanicie ortegalesa, con tan interesante grupo de construcciones prehistóricas... (MACIÑEIRA Y PARDO DE LAMA, "Notable grupo de círculos líticos...", pág. 197)).

7 Sobre la vida de don Santiago de la Iglesia vid. Xosé Antonio Fraga V́́zquez, "Santiago de la Iglesia", Album da ciencia [en línea] (2012), disponible en $<\mathrm{http}$ :/www.culturagalega.org/albumdaciencia/detalle. php?id=312> [Consulta:03/04/2018], FranCISCO José, “Aportaciones a la biografía del doctor La Iglesia",
} 
como bachiller, y su padre lo envió de vuelta a Santiago con diecisiete años para que estudiara teología. Una vez en la Universidad, descubrió que sus intereses se inclinaban más a la química, la botánica o la física que al dogma, así que abandonó aquellos estudios por los de medicina, muy en contra del deseo de su familia. Acabada la carrera, y tras un breve paréntesis en A Coruña, consiguió plaza en Ferrol (concretamente en Serantes, por aquel entonces municipio independiente), de donde ya no se movería y en donde, además de como médico, llegó a alcanzar una cierta notoriedad en el ámbito de la cultura y de la política.

En 1893, año en que descubrió los yacimientos mencionados, ejercía como médico forense y subdelegado de sanidad en la Villa Departamental. Era, además, profesor de Física y Química en la Escuela de Artes y Oficios, y un más que apreciado conferenciante. Los intereses de sus estudios eran variadísimos, e iban desde las diatomeas a la extracción industrial de yodo de las algas marinas, pasando por la historia, la geología y, por supuesto, la política. Hombre de fuertes convicciones republicano-socialistas ${ }^{8}$, será elegido este mismo año presidente del Comité del Partido Republicano Federal de Ferrol, como lo había sido a candidato a cortes por estos mismos partido y circunscripción dos años antes.

El hombre que se presentó en As Pontes aquel verano podría ser definido como un prototipo del "sabio" finisecular tan abundante en las villas y ciudades de la España del XIX. En un momento en que dos tercios de la población gallega era analfabeta ${ }^{9}$, y cuando la ciencia era tan reciente que muchas cosas carecían de nombre, aquellas personas con suficientes formación científica, capacidad intelectual, y curiosidad, aquellas personas conscientes de la realidad que los rodeaba, de los trabajos aún por hacer y de la urgencia que ya exigían muchos de ellos, se echaron a los hombros la ingente tarea de modernizar el país. Don Santiago de la Iglesia contribuyó a ella al promover la creación del Laboratorio Municipal de Ferrol, del Ateneo Científico y Literario, del Centro de Unión Republicana y del Centro Obrero de Cultura. En el mismo impulso ejerció la presidencia del Partido Republicano, del Areópago masónico de Ferrol ${ }^{10}$ y trabajó en la Sociedad Española de Historia Natural. Escribió artículos literarios como "Don Quijote redivivo"11,

Lar: revista del hospital gallego, 236-237 (1953), págs. 69-70, Arturo Souto Vizoso, “Sinopsis biográfica del doctor Santiago de la Iglesia y Santos”, Faro de Vigo (13-08-1981), pág. 28, Alberto Vilanova RodríGUEZ, voz "Santiago de la Iglesia y Santos", en Ramón Otero Pedrayo (dir.), Gran Enciclopedia Gallega, vol. 17, Gijón, Silverio Cañada, 1974, págs.203-204.

8 Santiago de la Iglesia y Santos, "Mi ideal”, El Motín (03-05-1924), pág. 2.

9 Narciso de GABriel, "El proceso de alfabetización en Galicia: un intento de explicación y comprensión”, Historia de la educación, 32 (2013), pág. 291.

${ }_{10}$ Boletín de procedimiento del Soberano Gran Consejo General Ibérico y Gran Logia Simbólica Española, 22 (1893), pág. 7.

${ }^{11}$ Xesús Alonso Montero, "Memorias cervantinas de un profesor cervantófilo", Hesperia, anuario de filología hispánica, 12, 1 (2009), págs. 5-26. 
y también históricos, como los "Apuntes sobre la vida de San Ignacio de Loyola" o este otro trabajo que aquí se presenta sobre la excavación de los yacimientos arqueológicos de As Pontes y que no llegó a publicar. Todo ello formaba parte de un mismo plan: sacar al país de su atraso multisecular. Es posible que el radio de acción de estos personajes fuera corto y que eso condicionara el impacto de su trabajo y, finalmente, su (práctico) olvido. Pero en conjunto, su contribución a la modernización del país (democratización del mismo, alfabetización, culturización, higienización) fue inmensa, y les quedó, como el mismo don Santiago reconoce, el consuelo (...) de haber aportado un sillar al futuro edificio, hoy por hoy todavia en cimientos (...).

\subsection{La excavación}

Llega pues este prohombre a As Pontes en julio de 1893. Tenemos noticia de que antes del día 14 ya estaba de vuelta en $\mathrm{Ferrol}^{12}$, por lo que podemos deducir que la excavación de los dos yacimientos referidos no duraría más de diez o doce días, y eso en el mejor de los casos. En ese corto espacio de tiempo, don Santiago, que se llama a sí mismo humilde obrero de la obra de la protohistoria gallega, hará en primer lugar un reconocimiento paisajístico y geológico de la zona. Después, levantará los trece túmulos de A Vilavella y revisará un dolmen expoliado por los lugareños en ese mismo lugar (no queda claro si es el de la noticia que había provocado su intervención u otro). Finalmente, documentará los tres cromlechs (les llamamos así ya que él así los considera) de A Mourela y, al mismo pie de éstos, revisará otro dolmen anteriormente saqueado y excavará, ex novo, otro más de los cuatro que logró distinguir en aquel paisaje.

La excavación arqueológica tuvo que ser entonces muy rápida, apresurada, algo de lo que don Santiago era perfectamente consciente. Cuántas dudas ayudaría a resolver una exploración detenida y concienzuda de esta comarca!, reflexiona en estas mismas páginas, a la vez que lamenta si las excavaciones se hiciesen de modo menos apresurado e inteligentemente dirigidas... La mayor parte del tiempo la dedicó al yacimiento del valle ([uno de los cromlechs de A Mourela] no ha sido explorado por los muchos días que en el examen de los monumentos anteriores había invertido, nos dice). La premura (y también su falta de pericia como arqueólogo) tuvo que hacer, necesariamente, mella en la calidad de la excavación.

En contraste, no debe dejar de subrayarse el detalle con que parece estudió los túmulos de A Vilavella, descritos uno a uno, señalando tanto lo que tenían en común como las peculiaridades de cada uno (cuando las había) y dando puntual cuenta de lo que en ellos encontró. Más aún, sabemos que se preocupó de com-

12 “Cartera del reporter”, El Correo Gallego (14-07-1893), pág. 2. 
probar la composición de cuatro flechas halladas en uno de los túmulos (cuyo análisis comparativo [con otras piezas que ya poseía] he llevado a cabo en mi laboratorio), o de asegurarse de la ausencia de restos humanos en los mismos mediante la recogida y análisis de muestras de tierra:

He pretendido determinar por el análisis del predominio de los fosfatos en el punto básico central de los túmulos comparando su proporción con la de otra tierra tomada a la misma profundidad a unos metros de distancia y no encontré discordancia sensible al análisis químico.

La formación científica de don Santiago se deja ver en esta repetida apelación a su laboratorio y a la química. Lo mismo sucede con la detallada descripción que nos ofrece de la geología de la zona y de la composición de las tierras y minerales que conformaban túmulos, dólmenes y cromleachs. Más allá de su mayor o menor pericia como arqueólogo, es a esa formación y mentalidad científica, así como a su tremenda curiosidad, a lo que debemos la existencia del texto que hoy presentamos como contribución a la historia de la arqueología gallega.

\subsection{El manuscrito}

El polígrafo santiagués dejo constancia de todo lo que venimos diciendo en un manuscrito que se custodia en la Biblioteca Xeral da Universidade de Santiago junto con otros documentos de su propiedad y de variada naturaleza, todos ellos bajo la signatura Ms 563 1, pudiendo considerarse su estado de conservación más que excelente. El manuscrito y el resto de la documentación fueron donados a la referida universidad por el propio Santiago de la Iglesia alrededor de 1928, junto con su colección de objetos arqueológicos y la mayor parte de su biblioteca ${ }^{13}$.

El texto fue redactado al menos dos años después de realizada la excavación. La alusión a la publicación de un fotograbado del vaso campaniforme por él encontrado en el no 684 de la Ilustración artística, de 4 de febrero de $1895^{14}$, así lo confirma. También podemos afirmar que no se trata de las notas simples de la excavación, que ya sabemos tanto que existieron como que circularon al menos entre sus amistades, sino más bien el borrador de un artículo que, por alguna razón que desconocemos, no llegó a publicarse. Esa sería la explicación más plausible para los espacios dejados en blanco (con la clara intención de ser rellenados posteriormente por él o por un tercero con los datos precisos), para las llamadas

\footnotetext{
${ }_{13}$ Santiago de la Iglesia y Santos, El Pueblo Gallego (03-03-1928), pág. 4.

${ }^{14}$ MACIÑEIRA Y PARDo DE LAMA, "Investigaciones prehistóricas en Galicia...".
} 
a las figuras que él mismo dibujó con esmero, y para alguna que otra digresión (incluyendo comentarios sobre obras ajenas) que, de no haber sido escritas para ser publicadas y leídas por otros, no tendrían ningún sentido.

Para la redacción del manuscrito utilizó la parte de atrás de unos formularios impresos que debían ser cubiertos con el orden del día de, muy posiblemente, la Junta Directiva del Partido Republicano del Ferrol, impresos que nunca llegaron a utilizarse y de los que él sacó buen provecho. Sin embargo, el papel de las hojas que contienen la portada y los dibujos antes referidos es de una mayor calidad. La portada, además, está realizada con una cuidada letra y con tinta negra, evidentemente distinta a la utilizada en el resto del manuscrito. Sólo un par de páginas fueron escritas a lápiz, allí donde se señalará. Los dibujos fueron realizados a plumilla y lápiz negro y azul. Las hojas están sujetas por dos grapas metálicas extraíbles, y están protegidas por una carpetilla que no es más que la cubierta de algún libro, o más bien libreta, reaprovechada. Encuadernadas con estos apuntes hay cuatro hojas que contienen reflexiones sobre ideas recogidas de sus lecturas de Mortillet, tituladas "Cerámica de la época robenhausiana", y que no se transcriben en el presente artículo al no considerarse pertinente.

A pesar de que la numeración de las páginas (hecha a lápiz) es incompleta, incongruente y no siempre guarda el orden numérico, el sentido del texto $y$, sobre todo, el encabalgamiento del mismo página a página, apenas dejan lugar a dudas

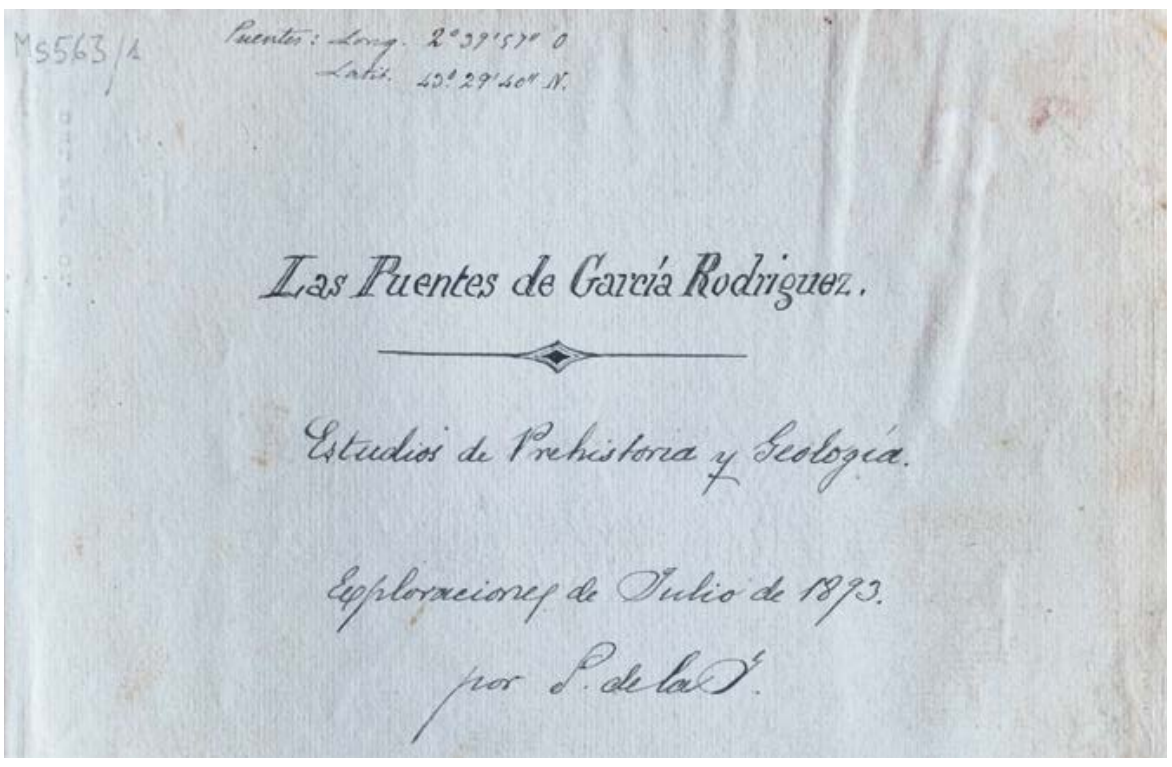

Fig. 1. Portada del manuscrito Las Puentes de García Rodríguez. Estudios de prehistoria y geología. Exploraciones de Julio de 1893 de Santiago de la Iglesia. 
sobre el orden en que fue escrito, que es el que se respeta en la transcripción. La explicación a todos estos errores de paginación (que no se corresponden, repetimos, con errores en el texto) puede estar en que ésta se realizó después de la redacción del texto y antes de su encuadernación definitiva.

\section{EDICIÓN DEL MANUSCRITO ${ }^{15}$}

[Cubierta:]

Puentes de García Rodríguez: sus estudios

[Anteportada:]

\section{LAS PUENTES DE GARCÍA RODRÍGUEZ}

Estudios de prehistoria y geología

Exploraciones de Julio de 1893

Por S. de la I.

[Antedede al título:] Puentes: long. 2o $39^{\prime} 57^{\prime \prime}$ Lat. $43^{\circ} 29^{\prime} 40^{\prime \prime} \mathrm{N}$.

\section{[Portada:]}

La comarca de las Puentes

Geología y protohistoria

por

S. de la I.

1893

\section{Las Puentes de García Rodríguez}

A $2^{\circ} 39^{\prime} 57^{\prime \prime}$ de long. O. y a $43^{\circ} 29^{\prime} 40^{\prime \prime}$ de lat. N. se halla la pequeña villa de Las Puentes de García Rodríguez ${ }^{16}$, cabeza de ayuntamiento perteneciente al Partido judicial de Ortigueira, en la Provincia de La Coruña, confinando con la de Lugo. Asienta la población en un valle limitado por montañas, entre cuyas faldas se desliza el río Eume, en aquel punto todavía poco caudaloso porque allí mismo, así como más abajo, Rivadeume ${ }^{17}$ recibe no despreciables afluentes. La

\footnotetext{
${ }^{15}$ En la transcripción se respetan la grafía, la ortografía, la puntuación y la disposición del texto del original. Cualquier aclaración se hace en nota al pie. Las interpolaciones dentro del texto van entre corchetes. Se respeta la colocación de las imágenes insertas en el texto original, y se añaden a éste las que fueron dibujadas aparte.

16 As Pontes de García Rodríguez (A Coruña).

17 Ribadeume (As Pontes).
} 


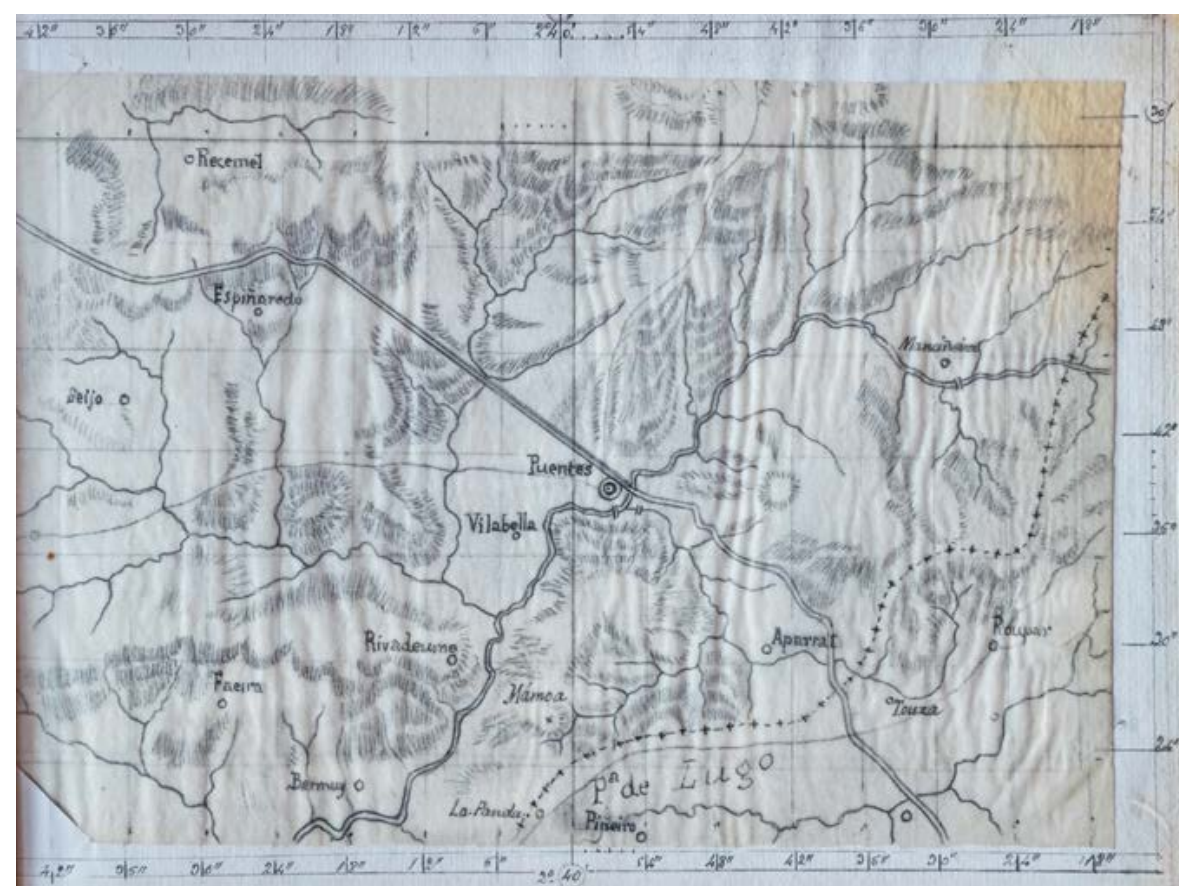

Fig. 2. Mapa de As Pontes de García Rodriguez elaborado por Santiago de la Iglesia.

extensa llanura así limitada, en uno de cuyos extremos asienta la villa, tiene por centro la aldea de Vilavella ${ }^{18}$, nombre tan significativo como el de Vila dos Mouros, porque revelan que ya antiguamente se recordaba que en esta aldeílla existió la villa-vieja $^{19}$ [y] porque en Galicia la tradición popular refiere a los moros todo cuanto procede de épocas que se pierden en la noche de la historia o de la proto-historia.

Los monumentos megalíticos y los curiosísimos objetos encontrados en este valle indican, desde luego, que allí hubo un centro de población con todos los caracteres que revelan una estación protohistórica, como más adelante se verá. El terreno perfectamente llano y cubierto de la activa vegetación que la extraordinaria humedad del clima origina en esta parte de Galicia, ofrece superficialmente una capa de humus y tierra vegetal de espesor que varía entre unos cuarenta centímetros y algunos metros en los puntos más próximos a las vertientes. A continuación, sigue arena, probablemente terciaria, pues faltan fósiles para afirmarlo, bajo la cual, y a veces faltando ésta, en contacto con la capa superficial se

\footnotetext{
18 Vilavella (As Pontes).

19 Los subrayados como en el manuscrito.
} 
encuentra el lignito que los naturales del país utilizan en el hogar. Gran parte del terreno ofrece la resonancia característica de los yacimientos turberos.

En algunos puntos próximos a las faldas de las montañas o de los accidentes orográficos de menor importancia, la acción del ácido carbónico del aire sobre los silicatos alumínico-potásicos y magnésicos originó el arrastre de finísima arcilla, en parte en vías de transformación en arcillitas y magnesitas de color grisáceo y suavísimo tacto, ya deleznables, ya más compactas y gráficas según la antigüedad y el modo y forma de sedimentación, separándose del detritus silíceo más grueso y denso que sedimentó más atrás o precipitó antes que el elemento feldespático.

Aunque todo lignito ocupa un lugar relativamente moderno en la serie de las capas fitogénicas, el de este valle parece relativamente antiguo y muy rico en elementos minerales que lo hacen de difícil combustión.

En el extremo del valle y más cerca de la población actual, en el punto en que el Eume aún no ha recibido el afluente de Vilavella, penetra entre una capa de lignito de considerable espesor que, buzando según 45 grados, forma un montículo en el que es posible la explotación a cielo descubierto.

Este lignito ofrece casi todas sus variedades, desde la pícea hasta iniciarse el transito al azabache, siendo en este caso negro, brillante, susceptible de talla y pulimento, pero poco duro. No es objeto de explotación alguna por falta de vías de comunicación y por la difícil extracción sin obras previas para el arrastre.

Los caracteres sucintamente apuntados determinan la clasificación de esta comarca como cuaternaria.

He aquí un corte del terreno en su estratificación más concordante y más común, aunque alterada en algunos puntos.

En algunos parajes otro aluvión más moderno recubre la arena terciaria.

El adjunto corte del yacimiento del principal depósito del lignito en la orilla del río, da idea de esta superposición.

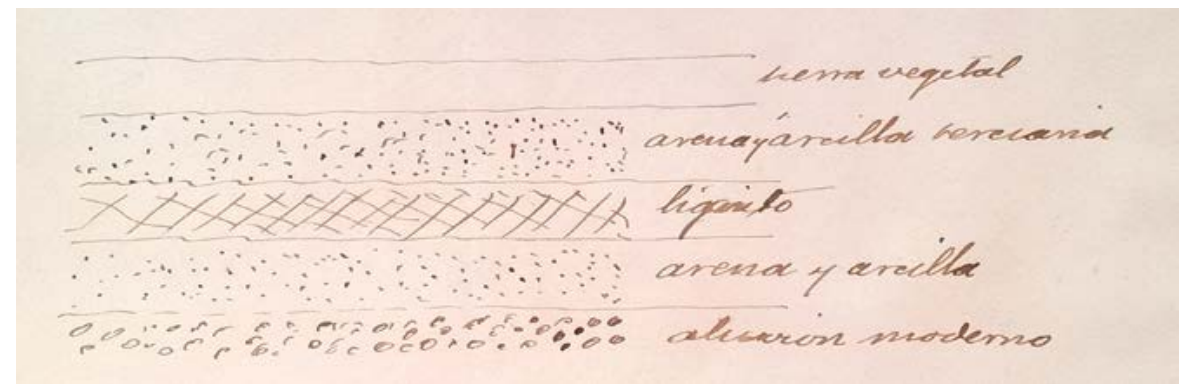

Fig. 3. Corte del terreno en el valle de As Pontes del manuscrito de Santiago de la Iglesia. 


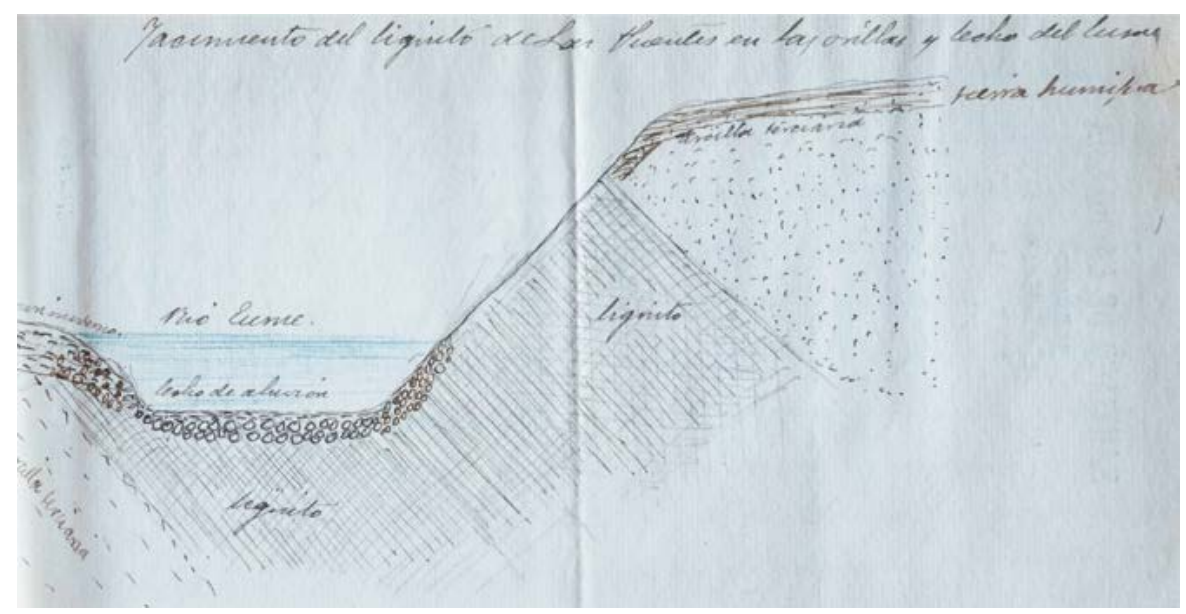

Fig. 4. Corte del terreno adyacente al río Eume en el manuscrito de Santiago de la Iglesia.

El anterior corte demuestra el enorme espesor del lignito en el cauce del río Eume y da idea de cuan distintas fueron las circunstancias que originaron ambos yacimientos. En este último, más moderno, puede apreciarse casi íntegra la estructura de las coníferas, probablemente pinos, que dieron origen al lignito. En el valle, en algunos puntos se hace turboso, o constituido por vegetales más herbáceos y menos leñosos cual si procediese de un lago de poco fondo o pantano que lentamente se fuese desecando y dando origen a vegetales monocotiledóneos, lago que es fácil de concebir si se mira al círculo orográfico que lo encierra, a la superficie perfectamente plana de la parte más profunda y a la relativa horizontalidad de la línea en que se han encontrado los monumentos protohistóricos de que vamos a ocuparnos, los cuales, en esta hipótesis, asentarían en el margen lacustre.

Agena [sic] a toda investigación protohistórica había permanecido esta comarca hasta $1895^{20}$ en que tuve noticia de que al extraer del terreno cultivado unas grandes piedras planas, se habían encontrado muchas hachas de piedra que los labradores se distribuyeron creyendo les sirviesen para afilar las guadañas con que siegan la hierba.

Sin pérdida de tiempo emprendí viaje a Las Puentes, ofreciéndoseme desde la primera investigación los caracteres geológicos que someramente dejo expuestos.

Las piedras del monumento saqueado habían sido llevadas en parte a otros puntos, fraccionadas y convertidas en cierres o cercados de los terrenos cultivados.

\footnotetext{
$\overline{{ }^{20} \text { Evidente error por } 1893 .}$
} 
Fue imposible reconstituirlo, ni aun aproximadamente, y solo sí afirmar por la descripción que se trataba de un dolmen.

Desde luego noté la existencia de muchos túmulus [sic] en la situación descrita y procedí a las excavaciones convenientes.

Tan uniforme era su estructura y forma, que describir uno es describirlos todos con leves diferencias en cuanto a altura y radio.

Trece he explorado y todos ellos están formados por un cono circular o ligeramente elíptico, truncado, con concavidad o hundimiento bastante marcado en la superficie de truncadura.

El orden de superposición de los materiales, marchando de fuera adentro es el siguiente:

1. Vegetación espontánea del país y detritus de la misma constituyendo una capa humífera de unos cincuenta centímetros cerca de la cúspide por metro y medio cerca de la base.

2. Otra capa de tierra más arcillosa y antigua con residuos de incineración consistentes en carbón, que he recogido, y de escaso espesor (10 o más centímetros en la cúspide, desapareciendo antes de la base)

3. Capa de cantos rodados, silíceos, de espesor que oscila entre un metro y 75 centímetros. Los cantos tienen un espesor variable pero pocas veces inferior a 30 centímetros. Esta capa tiene un espesor bastante regular en todos los puntos del monumento. Las más de las veces apenas si consiste más que en dos o tres cantos, considerados en el sentido de la sección.

4. Núcleo cónico constituido por tierra arcillosa plástica, oscura, casi negra, no escasa en humus enteramente alterado, sin indicio alguno de arena gruesa ni aun fina y enteramente distinta, sino cualitativa, cuantitativamente de la tierra que recubre exteriormente el monumento, en la cual no escasea el elemento silíceo de grano fino.

5. Base o suelo horizontal de aluvión silíceo de grano grueso o cascajo.

En el centro de la base del núcleo, simétricamente, esto es, en el eje, es en donde se han encontrado los objetos.

En algunos de los túmulos fue imposible encontrar indicio humano de ninguna clase, cual si el cadáver sepultado no llevase objeto alguno de posible conservación o fuera simplemente votivo, como quieren algunos arqueólogos.

El tamaño del túmulus no guardaba relación con el valor de los objetos contenidos en su interior. El más alto (cinco metros de altura por ocho de base) no contenía nada. Otro de dos metros de altura por tres de base contenía un collar o diadema de oro. 


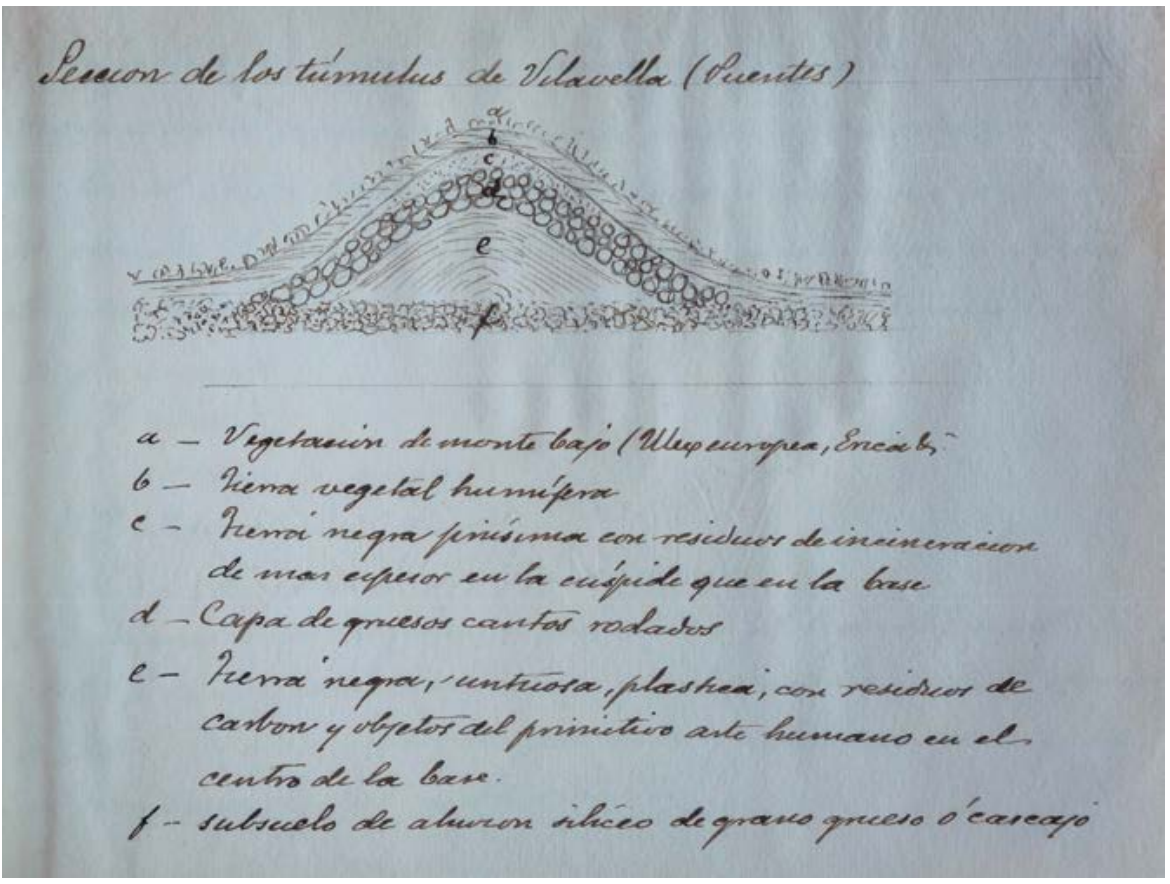

Fig. 5. Corte estratigráfico de los túmulos con la disposición estándar de las capas en el manuscrito de Santiago de la Iglesia.

Esta última capa que se encuentra, varía en los diversos monumentos explorados según el punto de su situación. En los del fondo del valle, o más bajos, es tal como la figura lo presenta. En los que están un poco más elevados, el orden de estratos del suelo por debajo del plano del túmulus es el siguiente:

1. Arcilla.

2. Arena y guijas.

3. Arena más fina.

4. Canto rodado o aluvión grueso.

En ninguno he llegado a encontrar el lignito, cual si este se encontrara más abajo en el fondo lacustre y como si estos monumentos empezasen en el margen y se escalonasen hacia la altura.

Enumerados por el orden en que fueron estudiados, resulta:

1er túmulus: cuatro metros de altura: nada. 
2. tres y medio metros de altura: hacha de piedra (pizarra anfibolífera) pulimentada [blanco] ${ }^{21}$ centímetros de largo

3. cuatro y medio metros de altura, nada

4. cuatro metros de altura, nada

5. tres metros de altura: restos de vasija de barro

6. tres y medio metros de altura: vasija de barro entera

7. cinco metros: el núcleo casi en totalidad constituido por canto rodado; nada

8. Cuatro metros: nada

9. tres metros $^{22}$ : diadema de oro, lanza y cinco puntas de flecha de cobre

10. tres metros y medio: nada

11. tres metros setenta y cinco cent.: nada

12. tres metros: nada

13. cuatro metros: ya anteriormente saqueado: nada

Pasando ahora a la descripción de los objetos hallados, tenemos en primer lugar un hacha de piedra pulimentada (pizarra anfibolífera) de estructura astillosa, de sección rectangular, de [blanco] cent. de longitud por [blanco] de lado en el centro y [blanco] de grueso. Véase fig. $n^{\circ}$ [blanco] Pesa [blanco] gramos.

Vasija de barro de forma de tulipán con dibujo de la época robenhausiana, consistente en líneas circulares y trazos punteados. Mide [14'5] centímetros de altura por [16] de ancho en la panza ${ }^{23}$. Su cochura es mediana: la suficiente para que [en] estado de sequedad tenga aceptable dureza, y harto incompleta para que empapada en agua como lo estaba al ser encontrada se desmenuzase entre los dedos. Un fotograbado de esta ánfora o lacrimatorio ha sido publicada en el $\mathrm{n}^{\mathrm{o}}$ [684, de 4 de febrero de 1895$]^{24}$ de la Ilustración Artística merced al diligente zelo [sic] de mi estudioso amigo el Sr. Maciñeira, que se apresuró a pedírmela para su reproducción cuando aún no estaba completa su posible restauración. Debo aquí rectificar una leve alteración de los hechos consignados por dicho Sr., y es que la vasija estaba en pie, agrietada por el enorme peso del túmulus, fragmentada, pero no estrellada en el momento del sepelio, puesto que, llena y rodeada

\footnotetext{
${ }^{21}$ Señalamos así los espacios dejados en blanco por el autor. Dando por supuesto que la intención era rellenarlos con los datos precisos y pertinentes, así lo haremos siempre que nos sea posible.

${ }^{22}$ Más arriba dijo que era de dos metros de altura por tres de base. En su Catálogo afirma que el mismo siquiera llegaba al metro de altura (Santiago de la IgLESIA y SANTOS, Catálogo de la sección de protohistoria gallega de la colección de Santiago de la Iglesia, Ferrol, El autor, 1907, pág. 6.)

${ }^{23}$ Datos recogidos de Luis Pericot García, "Los vasos campaniformes de la colección La Iglesia", Boletín de la Real Academia Gallega, t. 16, núm. 192 (1927), pág. 284.

${ }^{24}$ Aquí nos ofrece Santiago de la Iglesia la fecha a partir de la cual se debe datar este manuscrito.
} 
de tierra, todos sus trozos estaban colocados en el lugar que le correspondían; si fuese posible extraerla con la tierra que la rodeaba y trasladarla íntegra a esta ciudad, sería fácil ir desprendiendo toda su envoltura y ofrecerla a la vista entera aunque agrietada ${ }^{25}$. La coloración exterior es rojiza, la interior y la del barro es más amarillenta y la propia de la arcilla que la constituye.

No menos curioso es su perfecto modelado, desde luego o hecho a torno o por un procedimiento de análogo resultado. Las líneas circulares son perfectamente continuas sin que se note el principio ni el fin de su trazado. Y esta circunferencia en el área lateral de un sólido de revolución es imposible de obtener sin la revolución del mismo o de sus generatrices ${ }^{26}$. ¿Cómo explicar este trabajo acabado perfecto como lo pueden ser los de los actuales alfareros? Todos los autores convienen en que el torno es descubrimiento contemporáneo de la edad de hierro: mis hallazgos destruyen esta afirmación.

En esto como en todo yo no me permito afirmar nada: ofrezco mis datos y mis descripciones a la consideración de los arqueólogos encargados de sintetizar los hechos por todos los exploradores aportados.

La perfección del trabajo de estas vasijas que requirieron torno o instrumentos de resultados idénticos, yacentes con objetos del periodo neolítico y de cobre, es un dato más para afirmar, como ya se hizo hace tiempo y como corrobora mi ilustre amigo el Sr. Saralegui, que la clasificación de periodos protohistóricos no puede ser cronológica ni correlativa para los continentes, porque mientras un país se encontraba en la edad de piedra, quizá en la paleolítica, otro se hallaba ya en la mórgica o quizá ya en la del hierro, siendo posible por lo tanto que transacciones mercantiles rudimentarias o emigraciones originen la reunión de objetos de otro modo imposibles de armonizar.

Pero de todos modos, si admitimos con todos los arqueólogos que el culto a los muertos empieza en la época robenhausense, en que aparecen los primeros monumentos que resguardaban los cadáveres de las fieras y de los hombres, $\mathrm{y}$ relacionamos los túmulos de Las Puentes con su especial cerámica, también peculiar de la misma época, no será violento admitir que la estación de Las Puentes

\footnotetext{
${ }^{25}$ Las circunstancias que rodearon este descubrimiento fueron totalmente tergiversadas por Federico Maciñeira, tanto en la Ilustración Artística citada en el texto como en su posterior obra Federico MACIÑEIRA Y PARDO DE LAMA, "El vaso campaniforme y condiciones de sus intactos yacimientos tumulares en la estación de Puentes, del Cabo Ortegal", Atlantis, XVI, 3-4 (1941), págs. 365-367.

${ }_{26}$ También Maciñeira dudó de la existencia de un torno en este caso concreto (MACIÑEIRA Y PARDO DE LAmA, "Túmulos prehistóricos. Inventario descriptivo...”, pág. 15), pero ni Pericot (Pericot García, “Los vasos campaniformes...”), ni Carmelo Fernández (Carmelo Fernández IbÁÑEz, "Conservación y restauración de cerámica campaniforme: trabajo desarrollado en uno de los recipientes del monumento megalítico de As Pontes (A Coruña)", Gallaecia, 12 (1990), págs. 153-169), que estudiaron los vasos y sus fragmentos en profundidad, observaron tal cosa, confirmando que el trabajo había sido enteramente manual.
} 
corresponde al periodo de transición de la robenhausense a la mórgica o de fundición en la que todavía se conservaban restos, recuerdos, costumbres, útiles del periodo neolítico. Que no cambia la humanidad bruscamente en su modo de ser, ni hace saltos, como no los hace la naturaleza. Y menos difícil se hace creer esto, si se abraza lo que sucede en el corazón de las montañas de Galicia en que se observan ritos, costumbres seculares, útiles arcaicos al lado de los productos de la moderna civilización, el cuenco de barro y de madera al lado de la máquina de coser Singer cuyo ruido sorprende al viajero en los más recónditos despeñaderos en que se abra la cabaña de un carbonero o de un pastor.

Análogas consideraciones sujiere [sic] la diadema de oro, fig. [blanco].

Encontrose este collar o diadema en el mismo túmulus que contenía la lama y flechas de cobre. Mide [34'5] centímetros de largo [blanco] de ancho, está constituido por una lámina de oro muy delgada en la que no se percibe el más leve vestigio de martillo, la más ligera concavidad o abolladura. Su liga es de [20] kilates [sic] y su peso de [19] gramos ${ }^{27}$. Mi ilustre amigo el Sr. Saralegui reprodujo esta joya en la tercera edición de sus estudios célticos.

Como se ve en el dibujo, un extremo aparece roto y a juzgar por el otro y suponiéndolo simétrico debía alcanzar una longitud de 40 centímetros en estado de integridad. No estaría de más recordar aquí la perfecta analogía de esta joya con la que ceñía el cráneo de uno de los esqueletos descubiertos en la Cueva de los Murciélagos de Albuñol y publicada por el Sr. Góngora ${ }^{28}$ en sus Antigüedades Prehistóricas de Andalucia.

Muy cerca de este túmulus se exploró otro de análogas dimensiones, forma y estructura en cuyo centro de la base se encontraron numerosos fragmentos de una vasija enteramente igual, aunque el barro todavía era más blando y menos cocido. Estos fragmentos se hallaban dispersos en el área de la base, y distantes unos de otros algunos decímetros, ocupando un espacio mayor de un metro cuadrado, indicando que positivamente fue rota o estrellada antes de construir el monumento. Entre estos fragmentos existían vestigios abundantes de incineración y una arcilla roja idéntica al ocre, en pequeñas cantidades, aproximadamente como puñados sueltos ${ }^{29}$ cuyo color destacaba entre el negro intenso de la tierra que constituye el núcleo de todos los túmulus.

\footnotetext{
27 Datos tomados de Iglesia y SAntos, Catálogo de la sección de protohistoria gallega..., pág. 6.

${ }_{28}$ Manuel de Góngora y Martínez (1822-1884), catedrático de Historia Universal en la Universidad de Granada, inspector de antigüedades y editor. Como arqueólogo fue un innovador al darse cuenta de la importancia de la descripción minuciosa de los yacimientos, de su entorno y de los objetos allí encontrados, así como de la importancia de las ciencias auxiliares, método de trabajo que don Santiago de la Iglesia no dudó en adoptar, tal como vemos.

${ }^{29} \mathrm{Al}$ respecto nos dice Saralegui (SARALEgui y Medina, Estudios sobre la época céltica..., pág. 279) que se trataba de una sustancia ferruginosa preparada por la mano del hombre (sexquióxido de hierro, en
} 
Dicho queda que la labor de ambas vasijas es idéntica, consistiendo en circunferencias que alternadamente dejan entre sí un rayado punteado.

Si se considera la forma, estructura y ornamentación de estas vasijas, ánforas, lacrimatorios o como quiera llamárseles, vienen en ganas de traducir la descripción que hace Mortillet ${ }^{30}$ de la cerámica del periodo robenhausense que parece hecha en presencia de mis hallazgos: hasta tal punto coinciden. Y bajo la autoridad del mismo autor hay que admitir por ahora "que la cerámica no aparece en todo el Oeste de Europa hasta la época robenhausiense porque ni trazas de ella hay en las épocas precedentes: ha sido pues una importación”. En la cerámica de Las Puentes, como en la del Morbihan, en Inglaterra, en Hannover, en Bohemia; en Hungría, en Sicilia, en el vecino Portugal (habla Mortillet) las paredes exteriores son rojas.

Aquí como allí la cochura fue al aire libre e imperfecta.

Aquí como allá el vaso tiene forma de tulipán, se estrecha un poco en el medio y luego se ensancha en la abertura, y la base es redondeada o muy poco plana.

Aquí como allá los motivos son líneas y puntos, cintas y fajas punteadas: hasta aquí la analogía es perfecta.

Pero, aquí entra la notable diferencia: en los vasos de los autores robenhausenses no hay indicio de torno: los vasos están fabricados a mano: en los de Las Puentes hubo un aparato de rotación de resultados idénticos que para el caso es un torno.

\section{Armas de cobre}

De viejo viene discutiéndose si precedió el cobre al bronce o este a aquel, fundándose unos en la mayor facilidad del beneficio y fusión del mineral simple que en lo que supone conocimientos de metalurgia para efectuar una aleación. Como atrás dije, yo no afirmo nada: ofrezco hechos, datos, observaciones.

En un túmulus inmediato a los anteriores encontré la lama y cuatro puntas de flecha de las dimensiones y figura que demuestra el adjunto dibujo y que están formadas de cobre puro, a diferencia de otras armas de bronce que poseo procedentes de diferente comarca y cuyo análisis comparativo he realizado en mi laboratorio. $\mathrm{Si}$, por tanto, al lado de objetos de la época neolítica y de la robenhausiense se encuentran otros de la época llamada del bronce por los más de los

\footnotetext{
lenguaje vulgar tierra roja) que por su asociación a los demás objetos de ornato y defensa contenidos en las mámoas, parece indicar el uso que de este mineral hacian los antiguos pobladores de nuestro suelo para pintarse la piel...

${ }^{30}$ Louis Laurent Gabriel de Mortillet (1821-1898), antropólogo y arqueólogo francés. Su mayor contribución fue la periodización del paleolítico en función de las herramientas encontradas en distintos yacimientos cuyos nombres dieron el suyo a esos periodos, una nomenclatura que, tal como observamos, De la Iglesia adoptó en este trabajo.
} 
autores, y mejor llamados por Mortillet mórgica o de fundición, parece desprenderse de los hallazgos de Las Puentes un orden o correlación que confirmaría las opiniones del citado arqueólogo y que establecería el tránsito de la piedra pulimentada al cobre, y del cobre al bronce, que supone un adelanto por su mayor dureza y conservación, puesto que no pasa tan fácilmente como aquel al hidrocarbonato o cardenillo.

Hasta aquí los monumentos y objetos hallados en la llanura o valle de Las Puentes.

Necesario se hace establecer una distinción entre todo lo que dicho queda y los hallazgos en la cumbre de las montañas que rodean el valle, porque responden a otro tipo, siquiera hayan de incluirse en el periodo neolítico.

\section{Monumentos megalíticos}

En la cumbre de las montañas que dominan el valle de Las Puentes, a unos tres kilómetros, se encuentran monumentos megalíticos de un orden distinto.

He aquí los que yo he tenido la fortuna de ver y explorar el primero.

\section{$\underline{\text { Cromleachs }}$}

En la altura de una vasta planicie, sobre la montaña que domina el valle de Las Puentes y la llanura de Vila-vella, sepultados entre la vegetación lozana de Ulex europea (aliaga) se distingue con facilidad un gran cromleache [sic] de 20 metros de diámetro, circular, constituido por unas sesenta y tantas grandes piedras de cuarzo las más y más del doble número de otras más pequeñas dispuestas en dos filas, si no muy perfectamente marcadas en algunos sitios, muy perceptibles en con [sic] toda su extensión: cuatro grandes cantos del mismo blanco cuarzo situados al SE parecen indicar una entrada. Su centro, levemente cóncavo no ha sido explorado por los muchos días que en el examen de los monumentos anteriores había invertido.

A unos doscientos metros se halla otro no tan notable, pero bien característico de forma equivalente circular y de nueve metros de diámetro.

A medio kilómetro [sic] de distancia, bajando a la llanura en una pequeña meseta, se ven restos de otro que tendría unos treinta metros, de igual forma, y de idénticos materiales, a través del cual cruza el camino, lo que fue ocasión de que se fuesen extrayendo los cantos que lo formaban, empleándose en las cercas de las heredades.

Conforme con lo que asegura Mortillet (pag. 588) que sucede en la mayor parte de los cromleach en su obra La prehistoria (Mortillet 1885) los de Las 
Puentes están formados no por menhires, sino por piedras de pequeña dimensión, alcanzando sólo un volumen considerable en Escandinavia y en Inglaterra. En un principio se confundían con la misma denominación los crómlechs y los dólmenes. Hoy se reserva el primero de estos nombres con los espacios rodeados de piedras y se sigue llamando lo segundo a las cairns paleolíticas de soportes y cubierta de piedra que muchas veces ocupan el centro del crómlech ${ }^{31}$.

\section{Dólmenes}

En la meseta en que se asientan los cromleachs citados existen cuatro dólmenes, dos de los cuales se perciben de muchos kilómetros de distancia por encontrarse en la cúspide y punto que constituye el horizonte sensible del valle. Esta asociación del cromleach y el dolmen que es frecuente en el N. de Europa y que escasea en Francia abundando en el Mediodía según Cartaillac ${ }^{32}$, no tengo noticia de que se haya observado tan marcado en España como en Las Puentes.

Dos son los que se hallan en el mismo punto que los cromleaches descritos, equidistando de ellos unos cincuenta metros ${ }^{33}$. Fue explorado el uno por los labradores del país en 1892 en circunstancias verdaderamente cómicas, armados unos cuantos jóvenes de escapularios y amuletos de todas clases, fortalecidos por las favorables profecías de una anciana y amenizada la exploración por los repentinos e infundados temores de los unos y los chispeantes dichos de los otros. Ofrece el caso saludable enseñanza para reducir a su verdadero valor la tradición humana, falseada siempre, acompañada en el caso presente de cien embustes no creados por la fantasía popular al través de los tiempos, si no brotando falaz y fabulosa en su mismo origen, escoltada por la mentira que la malicia forja o por la alucinación que engendra la autosugestión. Allí, en el mismo lugar, al pie de las excavaciones, los mismos protagonistas cuentan con una frescura que no se sabe decir si mueve más a cólera que a risa, hablan de los extraños ruidos sentidos, de las llamaradas y humos que han visto salir y que les obligaron a tirar el hazadón [sic] y salir huidos.

Y si les interrogo con separación, la conformidad de sus embustes da pobre idea de la eficacia de las reglas de la lógica en cuanto al criterio de autoridad humana verificado entre la ignorancia y la superstición.

\footnotetext{
${ }^{31}$ Este párrafo fue escrito en un pedazo de hoja suelto y va precedido de un asterisco que se corresponde con una cruz del párrafo anterior, lo que indica que fue añadido después de redactado todo el texto a modo de aclaración.

${ }^{32}$ Émile Cartailhac (1845-1921), arqueólogo francés, fue profesor de Antropología y Prehistoria en la Universidad de Toulouse. Dedicó gran parte de sus estudios a la prehistoria de la Península Ibérica.

${ }^{33}$ Esta frase introductoria fue tachada por el autor, pero se incluye aquí porque consideramos que le da sentido a la frase siguiente.
} 


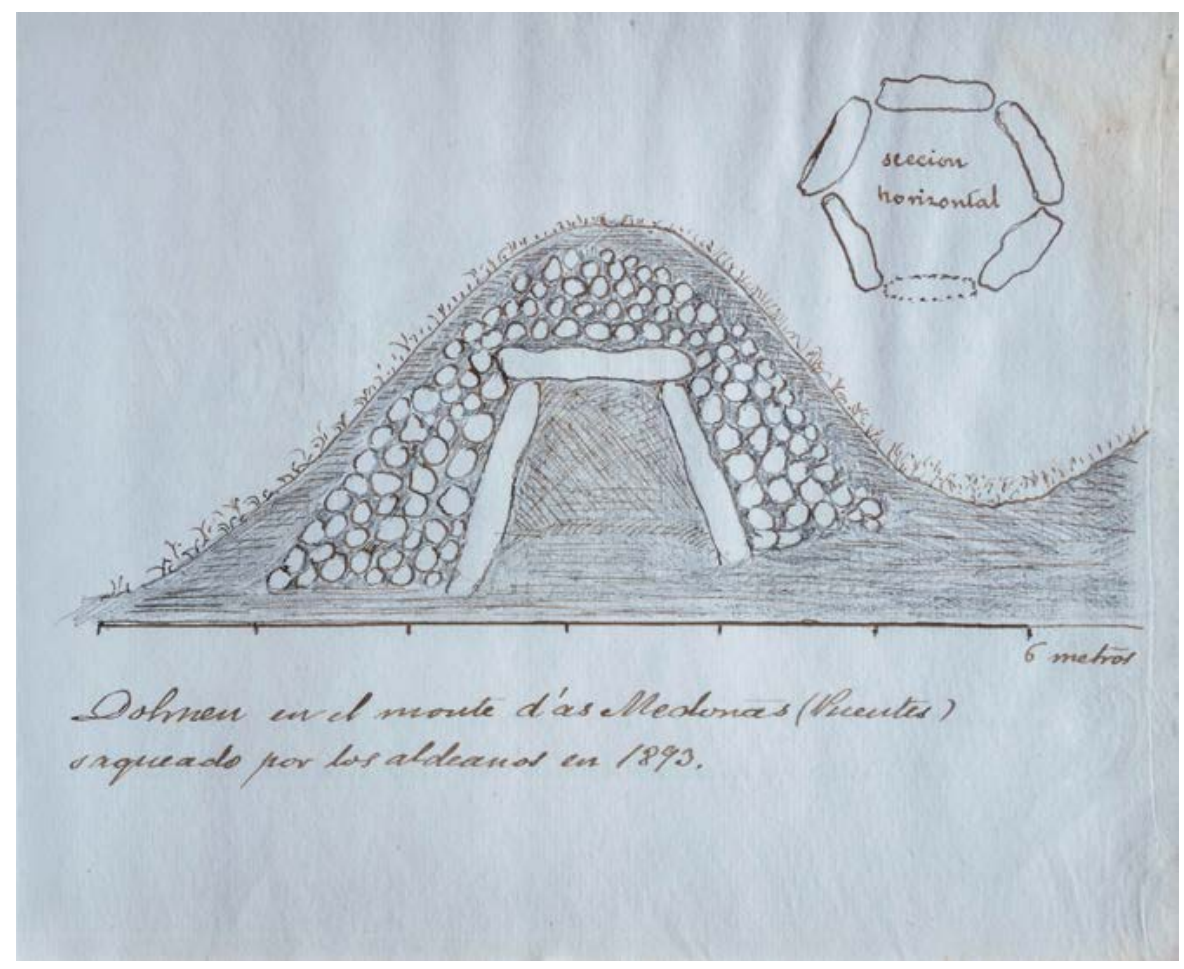

Fig. 6. Corte estratigráfico de uno de los dólmenes excavado por D. Santiago de la Iglesia.

Está constituido este dolmen por enormes piedras de forma aproximadamente trapecial con la base menor hacia arriba formando así a manera de bóveda que concluye de tapar otra no menos pesada losa colocada horizontalmente sobre ellas. El conjunto del monumento está cubierto por inmenso número de cantos rodados, idénticos a los de los túmulus descritos y que debieron haber sido transportados desde el aluvión del valle (próximamente tres kilómetros) mezclados con guijas de cuarcita, resultando así un dolmen con caracteres externos de cairn. Mucha debió ser la importancia de la persona cuyo cadáver reposaba allí para explicar la peregrinación numerosísima que supone tal número de cantos transportados con tan extraordinario trabajo y tal muchedumbre de gentes, o tal repetición del hecho piadoso de llevar allí una piedra nunca menor de una arroba de peso [unos doce quilos] y muchas veces de más de un quintal [unos 50].

De las averiguaciones más tenazmente realizadas resulta que los trabajos de los supersticiosos exploradores no tuvieron por premio otra cosa que el hallazgo de una piedra pulimentada de hechura de calabaza de unos ocho centímetros de altura, objeto que se llevó uno de los trabajadores, el que a su vez se lo regaló a 
un niño, quien con la inconstancia propia de la niñez acabó arrojando donde no recuerda. Quizá hayan pasado desapercibidos otros objetos prehistóricos de igual o mayor mérito, sobre todo por la circunstancia de que las piedras menudas, traídas allí de los próximos aluviones y que cubría todo el monumento no era alejada lo suficiente para que la exploración pudiera ser minuciosa y detenida.

El segundo de los dólmenes fue abierto y explorado por mí.

La forma exterior era la de un montículo de forma de cono muy acentuadamente truncado, presentando la superficie de truncadura ligero hundimiento en su parte central. La tierra extraída antes de llegar a la cubierta y paredes del dolmen es una arcilla finísima, eminentemente plástica, sin mezcla alguna de arena silícea, feldespática y teñida por el óxido de hierro.

Extraída una cantidad de esta finísima arcilla que no bajó de seis metros cúbicos, pudo aislarse el monumento formado por seis grandes piedras groseramente aplanadas, de una figura aproximadamente triangular, y en alguna trapezial [sic], convergiendo en la parte superior y cerrando un espacio de 1'75 de altura por 1'45 de diámetro. Este monumento ha sido visitado posteriormente por el Sr. Maciñeira que le asignó dimensiones bastante mayores a juzgar por las que consigna en su obra el Sr. Saralegui ${ }^{34}$.

El interior se hallaba completamente lleno de una arcilla todavía más fina y más plástica que la exterior, igualmente negra. El más prolijo examen, la extracción hecha a mano sin instrumentos, no dio por resultado el hallazgo del más insignificante objeto: el cadáver o cadáveres allí depositados lo fueron sin armas ni efectos conservables, sin cerámica, sin adornos, ni atributos litúrgicos, cosa ciertamente extraña si se tiene en cuenta la importancia que debiera tener el difunto a juzgar por la solidez del monumento y por su situación inmediata a los dos cromleachs.

Los materiales del monumento son idénticos entre sí y con varias otras piedras planas que abundan en algunas cercas y cerramientos de heredades poco distantes y quizá procedentes de otros dólmenes. Constituidos por una cuarcita vítrea, azulada, que en algunos puntos, si su estructura fuese mamilonar, simularían la calcedonia, y que por una de sus caras forma el tránsito a las pizarras de origen hidrotermal.

No menos notable es otro dolmen situado en el llano de Vilabella, concienzudamente estudiado por el Sr. Maciñeira, aunque ya había sido destrozado por los primeros y profanos exploradores. [Tachado: "que encontraron en él hachas de

\footnotetext{
${ }^{34}$ Saralegui (Leandro Saralegui y Medina, Estudios sobre la época céltica..., pág. 278) cita un recinto hexagonal de 2'5 metros de largo y 1'8 metros de altura, aunque no está nada claro que se trate del mismo dolmen. De hecho, el relato que hace Santiago de la Iglesia de estas prospecciones y el de Maciñeira (MACIÑEIRA Y PARDo DE LAMA, "Notable grupo de círculos líticos...”) son muy difícilmente compatibles.
} 


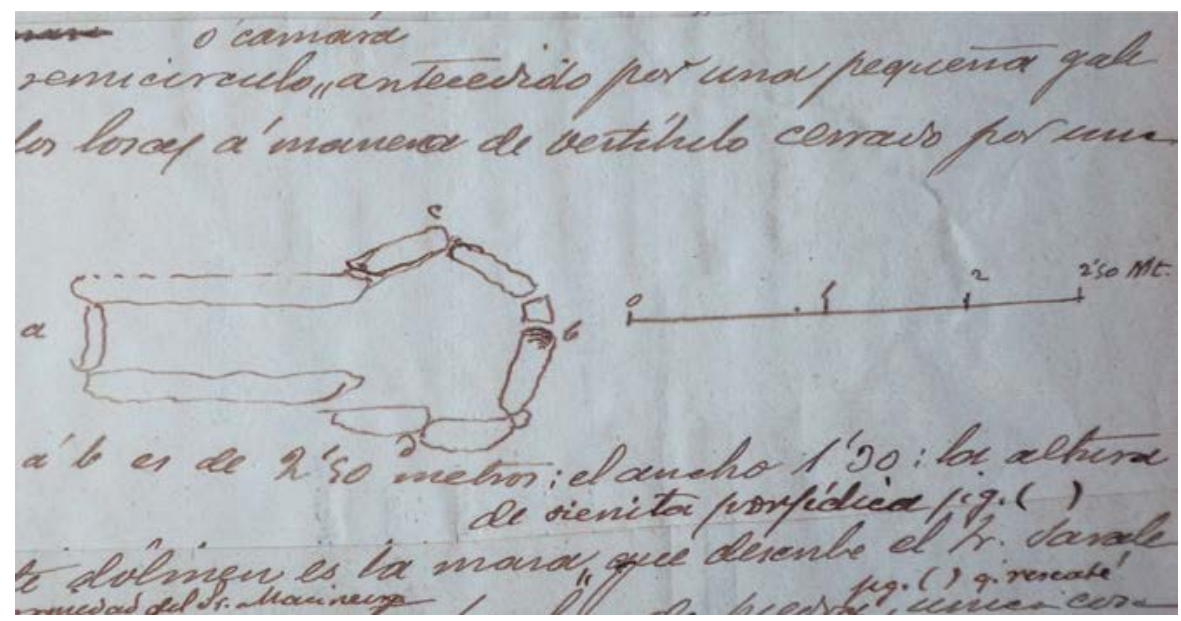

Fig. 7. Dibujo del dolmen de Vilabella junto a la escala de medida del manuscrito de Santiago de la Iglesia.

piedra (una de ellas la de la fig. [blanco])". Y otra versión también tachada: “que encontraron en él notables armas de piedra"]

La forma es un semicírculo o cámara antecedido por una pequeña galería formada por dos losas a manera de vestíbulo cerrado por una tercera piedra. La longitud de "a" a "b" es de 2'5 metros ; el ancho 1'30 ; la altura total 1' $60^{35}$.

Procedente de este dolmen es la maza de sienita porfídica fig. [8] que describe el Sr. Saralegui en su obra y que es propiedad del Sr. Maciñeira y las dos hachas de piedra fig. [blanco] que rescaté, única cosa que pudo ser salvada del saqueo $^{36}$.

Si en cuanto ${ }^{37}$ a cerámica aparece demostrado que la estación de las puentes pertenece a la época robenhausiana que hereda, por así decirlo, el arte de la magdalenense [sic], debe y puede afirmarse que, de aquella larga época, corresponde

\footnotetext{
${ }_{35}$ El descrito por Saralegui (SARALEGUI y Medina, Estudios sobre la época céltica..., pág. 277) a partir de las notas de Maciñeira, estaría constituido por un recinto semicircular de $0^{\prime} 90 \mathrm{~m}$. de diámetro y un pasillo formado por dos grandes piedras paralelas de 1'20, para un total de 2' $10 \mathrm{~m}$. de largo. El conjunto estaría cubierto por una losa elíptica de $1^{\prime} 60 \mathrm{~m}$. de diámetro menor. Ofrece también un dibujo idéntico al de don Santiago, por lo que se puede afirmar que se trata del mismo dolmen. Sin embargo, Maciñeira (MACIÑEIRA Y PARDo De LAMA, "Túmulos prehistóricos. Inventario descriptivo...", pág. 22) describe el dolmen del que se recuperó la maza de sienita como rectangular, de 1'90 de largo por 0'90 de ancho y l'45 de alto, por lo que se puede asegurar que se mezclan aquí las informaciones de dos dólmenes distintos.

${ }^{36}$ En su catálogo, las piedras son descritas como hachas de piedra de pizarra silícea pulimentada de $26^{\prime} 8 \times 5^{\prime} 3 \mathrm{~cm}$. la primera y de $28^{\prime} 3 \times 3^{\prime} 8 \mathrm{~cm}$. la segunda (IGLesia y SANTos, Catálogo de la sección de protohistoria gallega..., pág. 2).

${ }^{37}$ Tanto este párrafo como los dos siguientes fueron escritos a lápiz.
} 


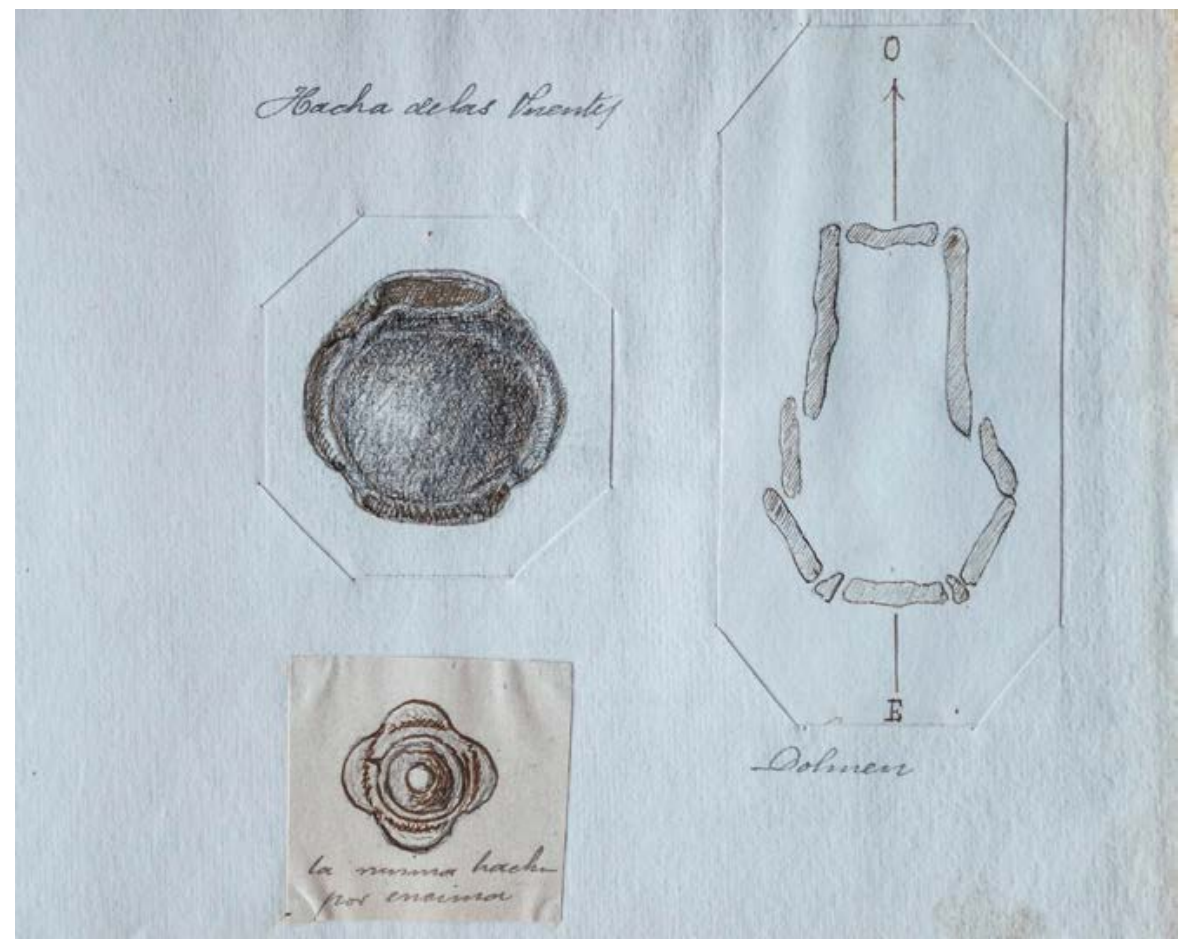

Fig. 8. Cabeza de la maza trilobulada y dibujo del mismo dolmen reproducido en la ilustración anterior.

al final, en que se une la robenhausense con el periodo del bronze: todavía al lado de las vasijas encontradas yacen puntas de flechas y lamas de bronze que revelan el principio de la época llamada por Mortillet morgien o de fundición, primera parte del periodo arqueológico del bronze o celta de Boule ${ }^{38}$ y Cartaillac, que el primero de estos geólogos hace preceder a la época larnaudica [sic] lacustre secundaria.

Si algo pudiera mover a confusión en la correlación que debe establecerse entre los objetos encontrados en la estación que estudiamos, sería la perfección del collar de oro, cuya regularidad de superficies parece fruto de un laminador mecánico: difícil se hace armonizar este grado de adelanto del arte con lo grosero y primitivo de las armas de bronze. Indudablemente las manos que fabricaron aquel no fabricaron estos objetos. Necesario se hace para darse cuenta de la consistencia de tales objetos recordar que España y muy especialmente Galicia fue el punto de encuentro de la raza invasora del sur, cualquiera que por otra parte

\footnotetext{
${ }^{38}$ Marcelline Boule (1861-1942), paleontólogo francés.
} 
sea su procedencia, y la raza, sino autóctona, preexistente en el país, conservando esta sus primitivos procedimientos, su industria, su arqueología característica y típica, sus armas de fines del periodo neolítico, sus hachas pulimentadas, sus túmulos, sus cromlechs, sus enterramientos, propiamente robenhausenses, y recibiendo de la gente invasora, que en este caso es probablemente la tercera raza, es decir, la de Furfooz ${ }^{39}$, procedimientos o al menos objetos pertenecientes a un estado mucho más adelantado, del cual es indicativo la joya adjunta. Y confirma esta razonable hipótesis la consideración de que lo natural es que abunden en una estación prehistórica cualquiera, los objetos de poco valor que son comunes, hijos de la industria indígena, no producto del cambio ni premio del vencedor, y que escasee aquello que procede de lejano país, aquello que es precioso y que puede considerarse ya como precio de compra o como botín de la victoria en las luchas entre tribus o de raza.

En cuanto a la absoluta carencia de restos humanos en monumentos exclusivamente consagrados a los muertos, no debe llamar la atención a quien conozca las condiciones metereológicas del país gallego, la enorme cifra que el pluviómetro arroja sobre todo en los lugares montañosos, de los cuales es acentuado tipo la comarca de Las Puentes. En el llano de Vilabella, al llegar al aluvión moderno que se halla escasamente a un metro de la superficie, brota el agua en los más de los puntos, y en otros se revela una humedad tal que haría imposible la conservación de sustancia orgánica alguna en un corto número de años. Y es cosa sabida de cuantos han tenido ocasión de intervenir en exhumaciones verificadas en los cementerios de las llanuras de esta comarca el estado de profunda alteración en que se halla el fosfato cálcico y magnésico del esqueleto después de haber desaparecido toda la parte orgánica, hasta el extremo de que los huesos más voluminosos, ricos en tejido compacto como el fémur, aún en su diploe, se deshacen entre los dedos cual si fuesen arcilla. He pretendido determinar por el análisis del predominio de los fosfatos en el punto básico central de los túmulos comparando su proporción con la de otra tierra tomada a la misma profundidad a unos metros de distancia y no encontré discordancia sensible al análisis químico. Por otra parte, si se considera la estructura del subsuelo y lo delgado de la capa vegetal en toda la llanura se comprenderá que las abundantísimas aguas pluviales, más o menos ricas en ácido carbónico, al filtrarse de arriba abajo y al encontrar un subsuelo perfectamente permeable que, obedeciendo a las leyes de la hidrodinámica las conduce a su punto de máximo declive, establece una constante renovación de las aguas subterráneas

\footnotetext{
${ }^{39}$ Mortillet (Gabriel de Mortillet, La Prehistorique antiquité de l'homme, $2^{\mathrm{a}}$ ed., Paris, Reinwald, 1885, págs. 611-612), dice que dans la grotte sépulcrale naturelle de Furfooz, près de Dinant (Belgique), existe une race tout à fait différente. (...) C'est une race nouvelle pour l'ouest de l'Europe, c'est donc une race étrangère qui a envahi le pays. Afirma que esta "raza" aparecería mezclada con la anterior ya en la época robenhausiense: Santiago de la Iglesia se muestra, una vez más, deudor de la obra de Mortillet.
} 
igual en sus efectos a un aparato de reemplazo tan usado en los laboratorios para separar las sustancias solubles de las insolubles. ¿Qué estraña [sic] pues que un lapso de tantos siglos no haya dejado el menor vestigio de osamentas allí en donde la inalterabilidad del carbón induce a creer casi con evidencia que yacía el cadáver al tiempo de construirse el monumento tumulario?

\section{(Adiciones a intercalar) $^{40}$}

Aún a parte de la autoridad de los que lo afirman, racional es creer con el P. Fita $^{41}$ que los inmigrantes celtas y la raza íbera aborigen tardasen siglos en fundirse para constituir los celtíberos, de igual modo que los galos se fundieron con la raza inmigrante para constituir los celto galos.

¿Pertenece a la población íbera primitiva o a la celtíbera la estación de Las Puentes?

He aquí una cuestión imposible de resolver por hoy sin más datos que los unipersonales de que aquí se hace mención.

Pero no parezca aventurado, ni menos atrevimiento, suponer que la inmigración celta al pasar de los Alpes a los Pirineos y al extenderse hacia el límite occidental, como afirma Cortés ${ }^{42}$ en su Diccionario Geográfico Histórico, conservando siempre su afición a las alturas, se hayan extendido a las últimas estribaciones de los Pirineos y a ellos deban atribuirse los cuatrocientos túmulos y monumentos inexplorados que se hallan diseminados por la sierra de la Faladoira que tan exactamente representa el mapa del ilustre Fontán ${ }^{43}$.

¿La índole totalmente distinta de los monumentos de la montaña (dólmenes y cromleaches) y de los túmulos del valle induce a creer que una raza mucho más antigua o más atrasada se mantuvo en algún tiempo, mejor dicho, durante algún tiempo en las sierras, mientras que otra población, quizá la población originaria, se mantenía en el valle de Las Puentes entonces lacustre, a juzgar por los caracteres geológicos? ¿Fue producto de sucesivas transacciones de cambio, comercio o botín de guerra el collar de oro cuya perfecta elaboración tanto dista de las armas neolíticas adjuntas y aun de las armas de cobre?

¡Cuántas dudas ayudaría a resolver una exploración detenida y concienzuda de esta comarca!

\footnotetext{
40 Titulillo a lápiz. Probablemente añadido a posteriori.

${ }^{41}$ Fidel Fita Colomé (1835-1918), jesuita catalán que sucedió a Menéndez Pelayo al frente de la Real Academia de la historia. Destacó como epigrafista por sus trabajos sobre la lengua latina y celtibérica.

${ }^{42}$ Miguel Cortés y López (1777-1854), sacerdote aragonés, miembro de la Real Academia de la Historia y autor del Diccionario Geográfico-Histórico de la España Antigua Tarraconense, Bética y Lusitana, publicado en Madrid, en 1836.

${ }^{43}$ Domingo Fontán Rodríguez (1788-1866), ilustrado gallego, miembro de la Real Academia de la Historia y director del Observatorio Astronómico de Madrid. Fue autor de la Carta Geométrica de Galicia, presentada en 1834 y publicada en París en 1845.
} 
Parece inclinarse el asunto a afirmar que la llanura fue estación lacustre, aunque hasta ahora la ausencia de palafitos y otros indicios no autorice para afirmarlo. El tiempo y las condiciones necesarias para que se formen los terrenos turberos induce a creerlo, mucho más si se considera que todos los túmulos por mi observados se encontraban en altura y situación tal que podía existir un lago a cuya orilla fuesen tangentes.

En este caso se explicaría que la población de los palafitos sepultase sus muertos en las márgenes. Pero no es sino congetura [sic] más o menos verosímil. Solo excavaciones amplias y repetidas, sondeos practicados en la parte más profunda de la planicie darán cumplida respuesta a estas hipótesis.

La época y la raza en que el hombre primitivo habitó estos lugares no[s] es por hoy completamente desconocido por la absoluta falta de datos para establecer una hipótesis racional.

Hasta facilidad hay en los actuales tiempos para satisfacer la constante interrogación que el espíritu formula y no ha de ser con suposiciones aventuradas con lo que se ha de llenar el vacío que reina en todo cuanto al hombre cuaternario se refiere. Y no ha de ser tan grande el respeto que nos merezcan autoridades como la de Mortillet que hayamos de admitir sin fundamentos muy sólidos la hipótesis del antropopiteco que establece el tránsito del terciario al cuaternario, sin que dato alguno cierto nos autorice para ello.

Limitémonos pues a hacer constar que la constitución geológica de la llanura de Vilabella es muy a propósito para haber constituido una estación lacustre análoga a las que pudieron haber existido en Carrucedo (Vivero), en las cercanías de Vares ${ }^{44}$, en Carregal (Corrubedo), en Traba (Lage) en la Carballeira (Valle de Barcala), en Doniños (Ferrol), Reirós, en Sta. Cristina y en muchos otros puntos. Geológicamente hablando, esta antigua estación debe estar cubierta por los aluviones modernos.

Y menos es aventurado suponer que existía una población distinta en la llanura y otra en la montaña que la circunda, como sucede en muchos puntos del extrangero [sic], más concienzudamente estudiados que Galicia.

(Mort) 487. Las estaciones lacustres o palafitos robenhausenses están generalmente muy cerca de las riveras. La mayor parte se encuentran aún bajo las aguas. Por lo tanto, con frecuencia están recubiertas de turba como en Robenhausen, habiéndose desarrollado la vegetación acuática sobre los puntos que ellos ocupaban. Los hay también que están enterrados bajo los aluviones y que están ahora en plena tierra, en seco. Los trabajos de la vía férrea los han hecho descubrir de este género en Villeneuve, Cantón del Vaud, y que han sido cubiertos por los aluviones del Ródano.

\footnotetext{
${ }^{44}$ Bares (Mañón, A Coruña).
} 
Debe también entrar en esta enumeración de los monumentos megalíticos de Las Puentes un cairn descrito y publicado con un fotograbado por el Sr. Maciñeira en la Ilustración artística. El interior de este monumento no es probable, pero si posible, que contenga dolmen ni otra construcción, pero no ha sido registrado por lo costosas y molestas que resultan siempre estas exploraciones en puntos como la localidad mencionada ${ }^{45}$.

Tal es a grandes rasgos la estación protohistórica de Las Puentes, en la que podría invertirse fructíferamente mucho dinero, si las excavaciones se hiciesen de modo menos apresurado e inteligentemente dirigidas, extendiéndolas a toda la sierra de la Faladoira, hoy verdadero desierto alejano [sic] de todo humano auxilio y en el que es necesario acampar en tiendas, pero que un tiempo debió ser asiento de numerosísima población a juzgar por los numerosísimos monumentos que allí yacen esperando una exploración que difícilmente se hará sin el concurso de los elementos oficiales.

Quepa al que suscribe, humilde obrero de la obra de la protohistoria gallega, el consuelo de haber sido el descubridor de tantos tesoros arqueológicos y de haber aportado un sillar al futuro edificio, hoy por hoy todavía en cimientos.

\section{EPÍlOGO: EL YACIMIENTO, HOY}

De los yacimientos arqueológicos así descritos por don Santiago de la Iglesia, como se dijo más arriba, no queda ni rastro. La actividad antrópica, especialmente dura y devastadora en el caso de la cubeta de As Pontes y en los montes que la circundan, no dejó piedra sobre piedra. Las veigas da Vilavella y dos Mouros, Illade, Ponte da Pedra, los parajes del valle de As Pontes por donde se desplegaban los túmulos primeramente estudiados por don Santiago de la Iglesia, fueron devorados por una enorme explotación minera a cielo abierto y por las labores a ella asociadas. Tampoco los enterramientos y los círculos líticos descubiertos por aquel entusiasta médico en uno de los montes que dominan el valle ${ }^{46}$, corrieron mejor suerte, a pesar de quedar a salvo de la mina. En su caso, fueron la construcción de un polígono industrial y, después, la de la autovía AG-64 Ferrol-Vilalba, las que hicieron desaparecer todo vestigio de actividad humana anterior a ellas. En todo caso, no debemos olvidar que, al margen de estas acciones concretas que supusieron su desaparición

\footnotetext{
${ }^{45}$ Este cairn no formaba parte de la estación arqueológica de A Mourela, sino que se encontraba medio quilómetro más arriba. Según Maciñeira, ya había sido excavado años antes y en él se habían encontrado un puñal de cobre y un torques, piezas que no llegó a ver (MACIÑEIRA Y PARDO DE LAMA, "Notable grupo de círculos líticos...”, pág. 19).

${ }^{46}$ María Martín da noticia de que ya en 1880 unos ingleses habían excavado un túmulo en A Mourela, en el que se habrían cobrado varias piezas arqueológicas (María Martín SEIJo, "Historia das investigacións sobre o megalitismo no concello das Pontes (A Coruña)", Cátedra: revista eumesa de estudios, núm. 10 (2003), pág. 302)
} 
total y definitiva, ambos yacimientos habían sido abandonados a su suerte durante casi ochenta años ${ }^{47}$, los que van desde los trabajos de don Federico Maciñeira (él mismo constató la práctica desaparición del círculo lítico mayor de A Mourela sólo diez años después de haberlo estudiado) hasta el inicio de las excavaciones de urgencia realizadas cuando su destrucción ya era inminente.

Creemos preciso destacar que en la última de estas excavaciones, provocada por la construcción de la citada autovía y centrada en el círculo lítico mayor, tras el estudio y análisis del mismo y de los materiales allí encontrados, se dató entre los siglos VII y XVII de nuestra era ${ }^{48}$. Sus restos, ya muy degradados en aquel momento, a los que se asociaron los de una cabaña medieval descubierta en esos mismos trabajos, son interpretados desde entonces dentro de un contexto agropecuario $^{49}$ muy alejado del tumular al que se habían asociado desde un primer momento forzando su interpretación como crómlech.

\section{BIBLIOGRAFÍA}

Alonso Montero, Xesús, “Memorias cervantinas de un profesor cervantófilo”, Hesperia, anuario de filología hispánica, 12, 1 (2009), págs. 5-26.

Boletin de procedimiento del Soberano Gran Consejo General Ibérico y Gran Logia Simbólica Española, 22 (1893).

Bonilla Rodríguez, Andrés y Fábregas Valcarce, Ramón (eds.), Círculo de engaños: excavación del crómlech de A Mourela (As Pontes de García Rodríguez), Santiago de Compostela, Andavira, 2009.

“Cartera del reporter”, El Correo Gallego (14-07-1893), pág. 2.

Eguileta Franco, José María, "O fenómeno megalítico na depresión de As Pontes de García Rodriguez (A Coruña): apuntes para un estado da cuestión”, en Andrés Bonilla Rodríguez y Ramón Fábregas Valcarce (eds.), Círculo de engaños: excavación del crómlech de A Mourela (As Pontes de Garcia Rodríguez), Santiago, Andavira, 2009, págs. 11-36.

\footnotetext{
${ }^{47}$ Un estado de la cuestión que abarca el estudio de la bibliografía sobre estos yacimientos, tanto la referida a los estudios de gabinete como a la generada por las excavaciones de urgencia realizadas entre 1988 y 1993 puede leerse en José María Eguileta Franco, "O fenómeno megalítico na depresión de As Pontes de García Rodriguez (A coruña): apuntes para un estado da cuestión”, en Andrés Bonilla Rodríguez y Ramón Fábregas Valcarce (eds.), Círculo de engaños: excavación del crómlech de A Mourela (As Pontes de García Rodríguez), Santiago, Andavira, 2009, págs. 11-36. El trabajo de María Martín antes citado, sirve para el mismo fin (María MARTín SEIJo, "Historia das investigacións sobre o megalitismo...)

48 Andrés Bonilla Rodríguez y Ramón Fábregas Valcarce (eds.), Círculo de engaños: excavación del crómlech de A Mourela (As Pontes de García Rodríguez), Santiago de Compostela, Andavira, 2009, págs. 257-259.

49 María Martín SeiJo, Ferrán antolín, Natàlia Alonso, Ramón Fábregas valCARCE y Andrés BoniLla RoDRíGUEz, "Prácticas agrícolas y gestión de los recursos forestales en el monte gallego entre los siglos VII y XVII ad.: El caso de A Mourela (As Pontes, A Coruña)", en Ana Maria dos Santos Bettencourt, Maria Isabel CAETANo Alves y Sérgio MonteIro-Rodrigues (eds.) Variaçoes paleoambientais e evoluçao antrópica no Quaternário do ocidente peninsular, APEC-CITCEM, 2010.
} 
Fernández Ibáñez, Carmelo, “Conservación y restauración de cerámica campaniforme: trabajo desarrollado en uno de los recipientes del monumento megalítico de As Pontes (A Coruña)", Gallaecia, 12 (1990), págs. 153-169.

Fraga Vázquez, Xosé Antonio, "Santiago de la Iglesia", Album da ciencia [en línea] (2012), disponible en $<\mathrm{http} / /$ www.culturagalega.org/albumdaciencia/detalle.php?id=312 $>$ [Consulta: 03/04/2018].

Francisco José, “Aportaciones a la biografía del doctor La Iglesia”, Lar: revista del hospital gallego, 236-237 (1953), págs. 69-70.

Gabriel, Narciso de, "El proceso de alfabetización en Galicia: un intento de explicación y comprensión", Historia de la educación, 32 (2013), págs. 289-313.

Iglesia y Santos, Santiago de la, Catálogo de la sección de protohistoria gallega de la colección de Santiago de la Iglesia, Ferrol, El autor, 1907 (Almanaque de Ferrol para el año de 1908, Ferrol, 1907).

Iglesia y Santos, Santiago de la, "Mi ideal", El Motín (03-05-1924).

Iglesia y Santos, Santiago de la, El Pueblo Gallego (03-03-1928), pág. 4.

Maciñeira y Pardo de Lama, Federico, "Investigaciones prehistóricas en Galicia", La Ilustración Artística, 684 (1895), pág. 126.

Maciñeira y Pardo de Lama, Federico, "Investigaciones prehistóricas en Galicia II”, La Ilustración Artística, 687 (1895), pág. 174.

Maciñeira y Pardo de Lama, Federico, "Notable grupo de círculos líticos y túmulos dolménicos de la cuenca superior del Eume", Arquivos do Seminario de Estudos Galegos, 2 (1929), págs. 197-231.

Maciñeira y Pardo de Lama, Federico, "El vaso campaniforme y condiciones de sus intactos yacimientos tumulares en la estación de Puentes, del Cabo Ortegal", Atlantis, XVI, 3-4 (1941), págs. 356-369.

Maciñeira y Pardo de Lama, Federico, "Túmulos prehistóricos. Inventario descriptivo de los doscientos ochenta y seis túmulos prehistóricos hasta ahora descubiertos en la avanzada comarca del Cabo Ortegal”, Boletín de la Real Academia Gallega, t. 24, núm. 277-280 (1944), págs. 15-34.

Martín Seijo, María, "Historia das investigacións sobre o megalitismo no concello das Pontes (A Coruña)", Cátedra: revista eumesa de estudios, núm. 10 (2003), págs. 301-314.

Martín Seijo, María; Antolín, Ferrán; Alonso, Natàlia; Fábregas Valcarce, Ramón y Bonilla Rodríguez, Andrés, "Prácticas agrícolas y gestión de los recursos forestales en el monte gallego entre los siglos VII y XVII ad.: El caso de A Mourela (As Pontes, A Coruña)", en Ana Maria dos Santos Bettencourt, Maria Isabel Caetano y Sérgio Monteiro-Rodrigues (eds.), Variaçoes paleoambientais e evoluçao antrópica no Quaternário do ocidente peninsular, APEC-CITCEM, 2010.

Mortillet, Gabriel de, La Prehistorique antiquité de l'homme, 2a ed., París, Reinwald, 1885.

"Muerte de un ilustre ciudadano: Ayer falleció don Santiago de la Iglesia", El Correo Gallego (10-11-1931).

Pereira González, Fernando, "O pensamento arqueolóxico e antropolóxico de Leandro Saralegui y Medina (1839-1910)”, Cuadernos de Estudios Gallegos, vol. 43, núm. 108 (1996), págs. 9-33. 
Pericot García, Luis 1927: "Los vasos campaniformes de la colección La Iglesia”, Boletín de la Real Academia Gallega, t. 16, núm. 192 (1927), págs. 283-291.

Saralegui y Medina, Leandro de, Estudios sobre la época céltica en Galicia, $3^{\mathrm{a}}$ ed., Ferrol, R. Imprenta y librería de R. Pita, 1894.

Souto Vizoso, Arturo, "Sinopsis biográfica del doctor Santiago de la Iglesia y Santos", Faro de Vigo (13-08-1981), pág. 28.

Vilanova Rodríguez, Alberto, voz “Santiago de la Iglesia y Santos”, en Ramón Otero Pedrayo (dir.), Gran Enciclopedia Gallega, vol. 17, Gijón, Silverio Cañada, 1974, págs. 203-204. 